\title{
Research on the Selection Strategy of Green Building Parts Supplier Based on the Catastrophe Theory and Kent Index Method
}

\author{
Zhenhua Luo, ${ }^{1,2}$ Jian He, ${ }^{1}$ Haize Pan, ${ }^{1}$ and Yiluan Yang ${ }^{1}$ \\ ${ }^{1}$ School of Civil Engineering and Architecture, Southwest Petroleum University, Chengdu 610500, China \\ ${ }^{2}$ School of Geoscience and Technology, Southwest Petroleum University, Chengdu 610500, China
}

Correspondence should be addressed to Jian He; 18782951044@163.com

Received 10 May 2016; Revised 5 August 2016; Accepted 14 August 2016

Academic Editor: Antônio G. de Lima

Copyright (C) 2016 Zhenhua Luo et al. This is an open access article distributed under the Creative Commons Attribution License, which permits unrestricted use, distribution, and reproduction in any medium, provided the original work is properly cited.

\begin{abstract}
At present, the green building and housing industrialization are two mainstream directions in the real estate industry. The production of green building parts which combines green building and housing industrialization, two concepts, is to be vigorously developed. The key of quality assurance in the assembly project is choosing reliable and proper green building parts suppliers. This paper analyzes the inherent requirements of the green building, combined with the characteristics of the housing industrialization, and puts forward an evaluation index system of supplier selection for green building parts, which includes product index, enterprise index, green development index, and cooperation ability index. To reduce the influence of subjective factors, the improved method which merges Kent index method and catastrophe theory is applied to the green building parts supplier selection and evaluation. This paper takes the selection of the unit bathroom suppliers as an example, uses the improved model to calculate and analyze the data of each supplier, and finally selects the optimal supplier. With combination of the Kent index and the catastrophe theory, the result shows that it can effectively reduce the subjectivity of the evaluation and provide a basis for the selection of the green building parts suppliers.
\end{abstract}

\section{Introduction}

Since 1910, after the concept of "housing industrialization" was proposed by the famous architect Pieter Groppi, many countries have put this concept into practice, leading to a major change in the residential area [1]. The engineers in China began to accept this concept since 1994. In 1999, the Chinese State Council issued "Notice on promoting the housing industrialization and improving the quality of housing. This accelerated the pace of developing the housing industrialization in China [2]. At the same time, green building is becoming the current development trend of the construction industry in the world. In 2012, the Chinese State Council issued the "Chinese Twelfth Five-Year Planning of Energy Conservation and Emission Reduction," which clearly put forward the requirements of developing green buildings [3]. So far, many real estate developers have begun to carry out the production of green building parts. However, the current standard system of green building development in China is underdeveloped; the standard system of housing industrialization is not comprehensive. This has caused many quality problems for construction parts, such as roof and toilet leakage, insulation wall cracking, the pipe wall leakage in kitchen and toilet, poor sound effects due to thin floor layer, and peculiar smell in kitchen and toilet. Therefore, the selection of green building parts suppliers is very important in the process of promoting green building and housing industrialization [4-7].

At present, the domestic and foreign research is mainly focused on green buildings or construction parts, and the study of green building parts suppliers is less. Wang and Guo (2007) used the grey correlation method for construction supplier selection [8]. This method needs to determine the optimal value of the index in advance, and the subjectivity is too strong. Yan et al. (2009) and Farzipoor Saen (2009), respectively, used data envelopment analysis (DEA) method for supplier selection and mainly compared the input and output to select the optimal supplier. The method requires 
TABLE 1: Elementary catastrophe model.

\begin{tabular}{llcc}
\hline Catastrophe model & Potential function & Control variable & State variable \\
\hline Fold catastrophe & $V(x)=x^{3}+a x$ & 1 & 1 \\
Cusp catastrophe & $V(x)=x^{4}+a x^{2}+b x$ & 2 & 1 \\
Swallowtail catastrophe & $V(x)=x^{5}+a x^{3}+b x^{2}+c x$ & 3 & 1 \\
Butterfly catastrophe & $V(x)=x^{6}+a x^{4}+b x^{3}+c x^{2}+d x$ & 4 & 1 \\
Hyperbolic umbilic & $V(x, y)=1 / 3 x^{3}-x y^{2}+a\left(x^{2}+y^{2}\right)-b x-c y$ & 3 & 2 \\
Elliptic umbilic & $V(x, y)=x^{3}+y^{3}+a x y-b x-c y$ & 3 & 2 \\
Parabolic umbilic & $V(x, y)=x^{4}+x^{2} y+a x^{2}+b y^{2}-c x-d y$ & 4 & 2 \\
\hline
\end{tabular}

a higher accuracy of the data, the application scope of the analysis is narrow, and the results of the analysis cannot fully reflect the strength of the suppliers $[9,10]$. Yang et al. (2010) used a fuzzy multiobjective decision-making model for supplier selection. However, it is difficult to establish a fuzzy multiobjective decision-making model for specific projects; this method does not have general applicability [11]. Peng and Li (2010) used entropy weight and TOPSIS for building suppliers selection [12]; Ruan and Chen (2011) used fuzzy VIKOR method for green construction supplier selection [13]. The calculated process of these two methods is complex, which is difficult to operate. Through previous research and combined with the proposed green building parts supplier evaluation system, this paper tries to apply the Kent index method combined with the catastrophe theory into the green building part supplier selection and evaluation. In this paper, the Kent index is used to evade the influence of subjective factors and choose measures to reduce subjective factors to the lowest. The catastrophe theory is used to understand and predict complex system behavior. Through the improvement of this method, it can be of objectivity and rationality in the selection process of green building part suppliers.

\section{Catastrophe Theory}

In 1972, French mathematician Ren Thom published the book Structural Stability and Morphogenesis, which is the earliest work that puts forward the independent and systematic exposition of the catastrophe theory. Catastrophe theory emphasizes the discontinuity or sudden conversion of the change process and studies the phenomenon and law of the nonlinear system from a stable configuration transition to another stable configuration; the aim is to predict the change behavior of the complex chaotic system. Catastrophe theory is a powerful mathematical tool to study the evolution of disordered system; it can better explain and predict the changes in nature and society and it has been widely used in the fields of ecology, engineering, social sciences, economics, and so on.

In the process of supplier selection, there are many uncertain factors, and the application of the catastrophe theory will be very good to reduce the impact of these factors on the results. At the same time, in the evaluation process of adopting catastrophe theory, the calculation of the weight is only used to sort the importance of indicators instead of being used to select the supplier directly. This will effectively reduce the subjectivity of the evaluation [14].

2.1. Elementary Catastrophe Model. Discontinuous leap phenomenon, whose control variable is not greater than 4 in nature and social life, usually can be described by 7 basic catastrophe models. All kinds of catastrophe models of potential function, control variables, and state variables are shown in Table 1 [15].

2.2. Normalization of Elementary Catastrophe Model. In the potential function equation of all control variables, the value change of any control variable will produce the state transition. The collections of all state transitions are merged into the different sets. And all the state transitions in different sets are in accordance with the following equation:

$$
\begin{gathered}
d V(x)=0, \\
d^{2} V(x)=0 .
\end{gathered}
$$

The elimination of the state variable in the upper type is to obtain the different set equation. The transformation and derivation of the different set equation can get some inherent association between control variables and state variables. The inherent association is normalized formula, which is also known as the catastrophe progression. By using normalized formula, each level of evaluation index system can be calculated, and finally the whole evaluation index system is obtained. In normal circumstances, there are fewer than 4 control variables and only 1 state variable in the catastrophe model of the index system. The main catastrophe models which researchers usually use are the cusp catastrophe, swallowtail catastrophe, and butterfly catastrophe.

The normalization formula for cusp catastrophe is

$$
\begin{aligned}
& x_{a}=\sqrt{a}, \\
& x_{b}=\sqrt[3]{b} .
\end{aligned}
$$

The normalization formula for swallowtail catastrophe is

$$
\begin{aligned}
& x_{a}=\sqrt{a} \\
& x_{b}=\sqrt[3]{b} \\
& x_{c}=\sqrt[4]{x}
\end{aligned}
$$




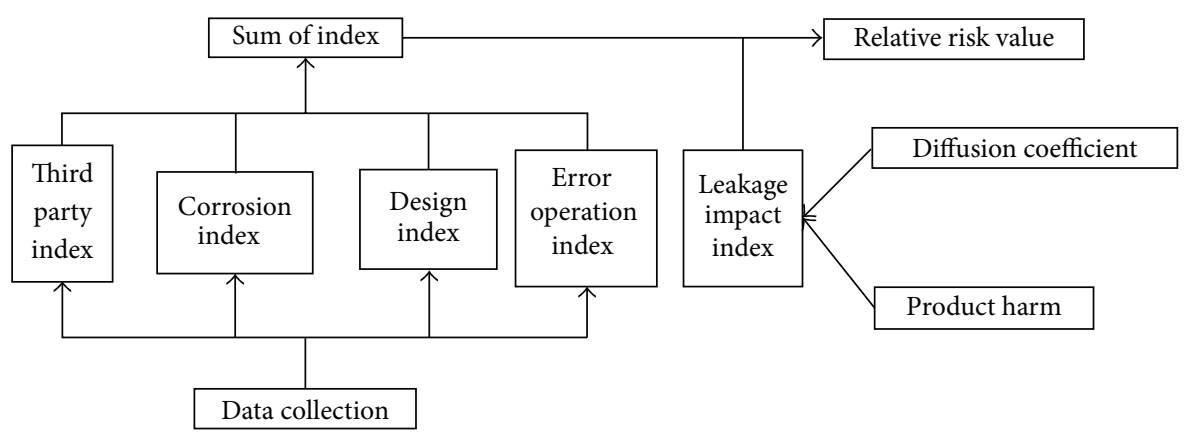

FIGURE 1: Evaluation process of the Kent index method.

The normalization formula for butterfly catastrophe is

$$
\begin{aligned}
& x_{a}=\sqrt{a}, \\
& x_{b}=\sqrt[3]{b} \\
& x_{c}=\sqrt[4]{x} \\
& x_{d}=\sqrt[5]{x}
\end{aligned}
$$

\section{Kent Index Method}

In 1985, the United States Columbus Battelle Institute published the article "Guideline for Hazard Evaluation Procedures," which first proposed to use the index method to assess the risk of oil and gas pipelines. In 1992, W. Kent Muhlbauer improved the Kent index method and introduced this method in Pipeline Risk Management Manual. First of all, on the basis of oil and gas pipeline's damage conditions, the Kent index method formulates corresponding Kent index to differentiate the risk levels of engineering project. Then the Kent index method analyzes the independent factors of each pipeline and meanwhile analyzes the diffusion risk index and the medium influence coefficient of the material in the pipe, so as to obtain the assessment of various risk factors that caused damage to the oil and gas pipelines, calculation of the sum of index, and the leakage impact index. Finally, the relative risk value is obtained by the sum of index divided by the leakage impact index. The relative risk value is relative to the risk level and is used to obtain the risk grade of the specific project. The specific process of the Kent index method is shown in Figure 1.

According to the probability theory, if we want to make a precise prediction of the event, we often need enough samples, but most of the time the samples are not enough. At the same time, too many assumptions can lead to inaccurate results. The Kent index method was applied to evaluate project risk; its advantage is that it did not avoid the important role of subjective factors in the risk assessment but took some feasible measures to reduce the impact of subjective factors, so as to effectively enhance the credibility of evaluation results. Similarly, the selection of the green building parts suppliers is also through the analysis of various indicators to launch each supplier's scores, introduce Kent index method, and improve its evaluation model, making it adapt to the choice of supplier evaluation. This method will be able to effectively reduce the influence of subjective factors, and it is easy to operate and easy to calculate $[16,17]$.

\section{The Establishment of Evaluation Index System of Green Building Parts Supplier}

Different from the traditional construction materials, construction parts of housing industrialization are standardized designed and processed into small parts in the factory and then installed and spliced at the construction site, so as to improve the construction efficiency and the quality of housing.

Each construction part which is relative to the specific construction project has played an indispensable role in the process of assembly. With a certain size and function, each construction part is unique. Thus it requires a complete set of standards to measure the reliability of its performance. However, the housing industrialization industry in China has just started, so that the corresponding system is not perfect. Meanwhile, the green building advocates the concepts of energy saving, land saving, water saving, material saving, and environmental protection in the whole life cycle, which require the green building to have features of health comfortability, economical losses, energy consumption, efficient use, and harmonious coexistence with nature.

On the basis of the related literature review [18-21], this paper chooses parts of the evaluation index for suppliers, combined with the characteristics of the housing industrialization and the green building, and then establishes the evaluation index system of green building parts (nonpatented products) supplier, which contains 4 items of primary indicators, 14 items of secondary indicators, and 47 items of tertiary indicators, as shown in Table 2.

\section{Improved Model Based on Kent Index and Catastrophe Theory}

5.1. The Establishment of the Model. According to the characteristics of the green building, the evaluation index of the supplier can be divided into 4 categories: product index, enterprise index, green development index, and cooperation 
TABLE 2: Evaluation index system of green building parts supplier.

\begin{tabular}{|c|c|c|}
\hline Primary index & Secondary index & Tertiary index \\
\hline \multirow{4}{*}{ Product index $\left(I_{P}\right)$} & \multirow{4}{*}{ Quality $\left(I_{P 1}\right)$} & Quality management level $\left(I_{P 11}\right)$ \\
\hline & & Product sample pass rate $\left(I_{P 12}\right)$ \\
\hline & & Repair and return rate $\left(I_{P 13}\right)$ \\
\hline & & Product performance $\left(I_{P 14}\right)$ \\
\hline \multirow{3}{*}{ Product index $\left(I_{P}\right)$} & \multirow{3}{*}{ Price $\left(I_{P 2}\right)$} & Product price $\left(I_{P 21}\right)$ \\
\hline & & Procurement and transportation costs $\left(I_{P 22}\right)$ \\
\hline & & Installation cost $\left(I_{P 23}\right)$ \\
\hline \multirow{3}{*}{ Product index $\left(I_{P}\right)$} & \multirow{3}{*}{ Time $\left(I_{P 3}\right)$} & Early completion rate $\left(I_{P 31}\right)$ \\
\hline & & On time delivery $\left(I_{P 32}\right)$ \\
\hline & & Flexible delivery capability $\left(I_{P 33}\right)$ \\
\hline \multirow{4}{*}{ Enterprise index $\left(I_{E}\right)$} & \multirow{4}{*}{ Professional skill $\left(I_{E 1}\right)$} & Contract performance $\left(I_{E 11}\right)$ \\
\hline & & Similar project experience $\left(I_{E 12}\right)$ \\
\hline & & Quality of personnel $\left(I_{E 13}\right)$ \\
\hline & & Enterprise qualification $\left(I_{E 14}\right)$ \\
\hline \multirow{3}{*}{ Enterprise index $\left(I_{E}\right)$} & \multirow{3}{*}{ Market position $\left(I_{E 2}\right)$} & Market share $\left(I_{E 21}\right)$ \\
\hline & & Customer satisfaction $\left(I_{E 22}\right)$ \\
\hline & & Corporate reputation $\left(I_{E 23}\right)$ \\
\hline \multirow{4}{*}{ Enterprise index $\left(I_{E}\right)$} & \multirow{4}{*}{ Financial situation $\left(I_{E 3}\right)$} & Registered capital $\left(I_{E 31}\right)$ \\
\hline & & Circulating fund $\left(I_{E 32}\right)$ \\
\hline & & Return on equity $\left(I_{E 33}\right)$ \\
\hline & & Asset liability ratio $\left(I_{E 34}\right)$ \\
\hline \multirow{3}{*}{ Enterprise index $\left(I_{E}\right)$} & \multirow{3}{*}{ Innovation ability $\left(I_{E 4}\right)$} & Innovative capital investment $\left(I_{E 41}\right)$ \\
\hline & & Innovative personnel input $\left(I_{E 42}\right)$ \\
\hline & & Product technical innovation rate $\left(I_{E 43}\right)$ \\
\hline \multirow{4}{*}{ Green development index $\left(I_{G}\right)$} & \multirow{4}{*}{ Environmental conditions $\left(I_{G 1}\right)$} & Environmental protection investment conditions $\left(I_{G 11}\right)$ \\
\hline & & Green technology application $\left(I_{G 12}\right)$ \\
\hline & & Staff environmental awareness $\left(I_{G 13}\right)$ \\
\hline & & Environmental management system certification $\left(I_{G 14}\right)$ \\
\hline \multirow{4}{*}{ Green development index $\left(I_{G}\right)$} & \multirow{4}{*}{ Energy consumption level $\left(I_{G 2}\right)$} & Unit parts of energy consumption $\left(I_{G 21}\right)$ \\
\hline & & Unit parts of material consumption $\left(I_{G 22}\right)$ \\
\hline & & Unit parts of human consumption $\left(I_{G 23}\right)$ \\
\hline & & Other resource consumption $\left(I_{G 24}\right)$ \\
\hline \multirow{4}{*}{ Green development index $\left(I_{G}\right)$} & \multirow{4}{*}{ Environmental effect $\left(I_{G 3}\right)$} & Construction noise pollution $\left(I_{G 31}\right)$ \\
\hline & & Construction solid waste pollution $\left(I_{G 32}\right)$ \\
\hline & & Construction pollution of gas and water $\left(I_{G 33}\right)$ \\
\hline & & Radionuclide emission $\left(I_{G 34}\right)$ \\
\hline \multirow{2}{*}{ Green development index $\left(I_{G}\right)$} & \multirow{2}{*}{ Recycling and utilization $\left(I_{G 4}\right)$} & Building parts recovery rate $\left(I_{G 41}\right)$ \\
\hline & & Construction parts recycling and reutilization $\left(I_{G 42}\right)$ \\
\hline \multirow{2}{*}{ Cooperation ability $\left(I_{C}\right)$} & \multirow{2}{*}{ Cooperation intention $\left(I_{C 1}\right)$} & Cooperation intention of the project $\left(I_{C 11}\right)$ \\
\hline & & Long-term cooperation intention $\left(I_{C 12}\right)$ \\
\hline \multirow{2}{*}{ Cooperation ability $\left(I_{C}\right)$} & \multirow{2}{*}{ Degree of cooperation $\left(I_{C 2}\right)$} & Corporate culture compatibility $\left(I_{C 21}\right)$ \\
\hline & & Enterprise information exchange level $\left(I_{\mathrm{C} 22}\right)$ \\
\hline
\end{tabular}

ability, which, respectively, form the corresponding relationship with the indicators of Kent model. The corresponding relationship of the improved model is shown in Figure 2.

Product index of supplier evaluation system is measured by three indicators such as quality, price, and time. The quality of products, the level of price, and the elasticity of supply time can be well judged by the actual data, and the scores of these indexes will have a direct impact on the total points of the green building parts suppliers. The information of the corrosion index and the error operation index in the pipeline risk assessment is also obtained through the analysis of the relevant data, and the quality of these two indexes will have a direct impact on the safety of the pipeline, which plays an important role in the pipeline risk assessment. Therefore, 


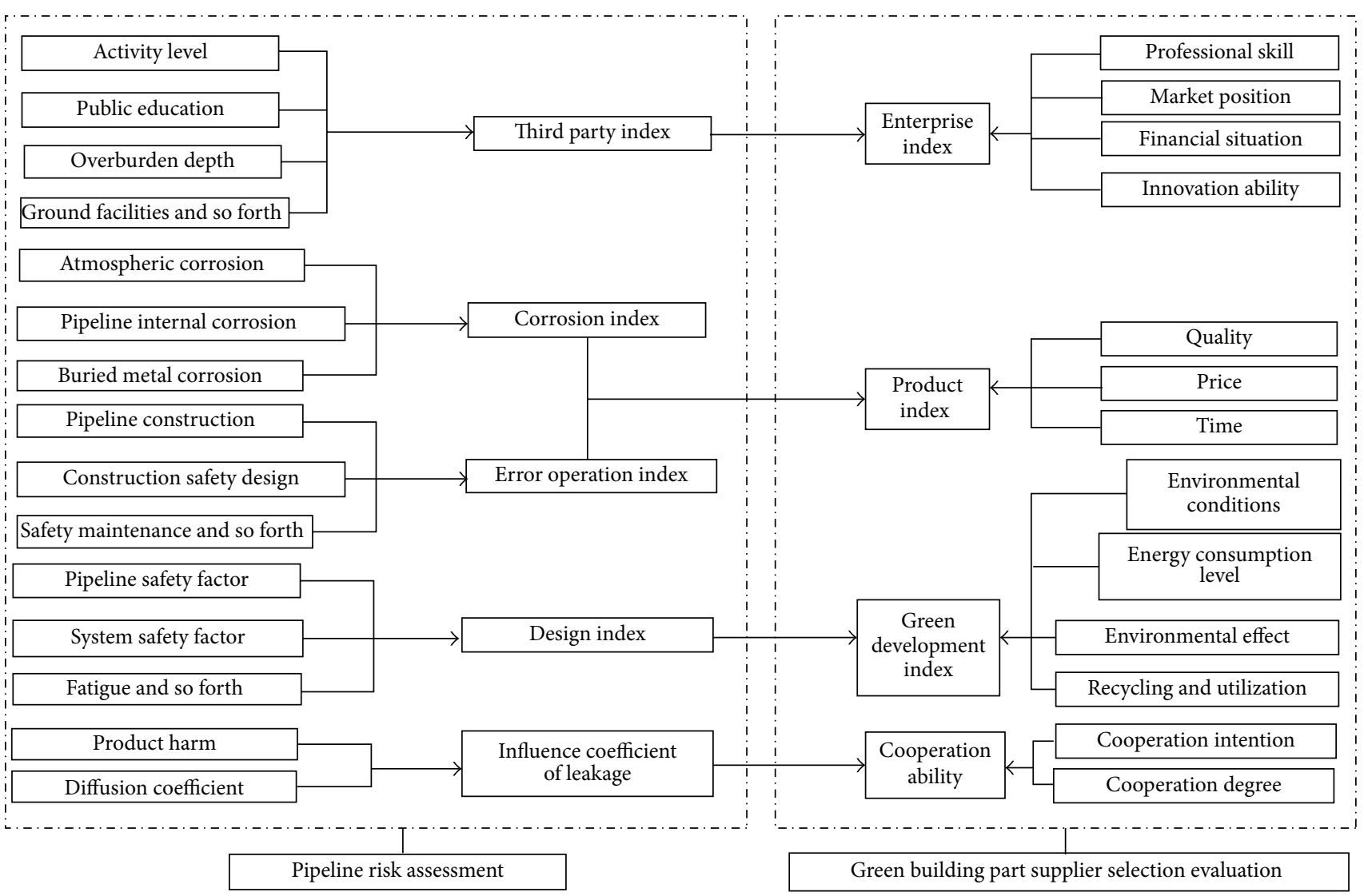

FIGURE 2: The improved model.

in this paper the product index is corresponding to the corrosion index and the error operation index of the pipeline risk assessment.

Enterprise index of supplier evaluation system is mainly used to measure the overall strength of suppliers; its evaluation measurements are supplier's business level, market position, financial situation, and innovation ability. In general, if the suppliers' overall strengths are at the same level, the enterprise index of each supplier has no more difference. Thus the enterprise index belongs to auxiliary index in the evaluation process. The third party index of pipeline risk assessment takes activity level, public education, and cover thickness as a judge; its impact on the safety of pipeline from the same area is almost the same. Therefore, in this paper the enterprise index is corresponding to the third party index of the pipeline risk assessment.

Green development index of supplier evaluation system directly determines whether the construction parts are in accordance with the specific requirements of green building. This index takes the situation of environmental protection, level of energy consumption, environmental impact, and recovery utilization as measurements, and these criteria will directly affect the selection of parameters and the final design outcome during the design process of the green building parts. According to the above point of view, green development index of supplier evaluation system and the design index of the pipeline risk assessment almost have the same role in the evaluation process. Therefore, this paper takes these two indexes corresponding to each other.

Cooperation ability index of supplier evaluation system reflects the cooperation ability of enterprise with related strategic partners or working partners. The score of this index is positively correlated with the score of supplier evaluation. Meanwhile the leak impact index of the pipeline risk assessment is measured by product harm and diffusion coefficient, and the size of the leak impact index is positively correlated with the size of the pipeline risk assessment. Thus it can be seen that cooperation ability index of supplier evaluation system and the leak impact index of the pipeline risk assessment have similar meaning in the evaluation procedure. Therefore, this paper takes the cooperation ability of supplier evaluation system corresponding to the leak impact index of the pipeline risk assessment.

5.2. The Calculation of the Model. In the process of the selection of green building parts suppliers, because of the existence of cross effect of the complex relationship between the various indicators, it is so difficult to show the effect of evaluation by the simple addition of each index where the computational methods need appropriate improvements.

(1) According to the characteristics of catastrophe theory, the index of the same attribute of each level should be sensitivity sorted before the evaluation. The more important the index should be put in the former, the less important 


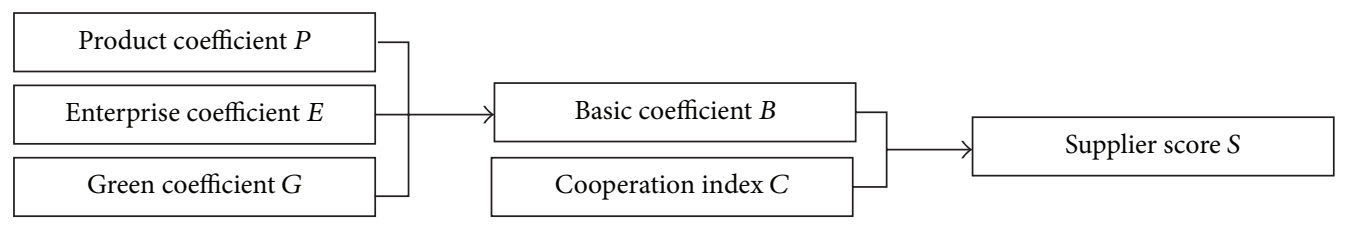

FIGURE 3: Evaluation frame of green building parts supplier.

TABle 3: Definition of the judgment matrix scale.

\begin{tabular}{lc}
\hline Scaling $a$ & Meaning \\
\hline 1 & $\begin{array}{r}\text { Factor } i \text { compared with factor } j \text { is equally } \\
\text { important }\end{array}$ \\
3 & $\begin{array}{c}\text { Factor } i \text { compared with factor } j \text { is slightly } \\
\text { important }\end{array}$ \\
5 & Factor $i$ compared with factor $j$ is obviously \\
important
\end{tabular}

the index should be placed in the post. This paper uses the characteristic vector method of analytic hierarchy process (AHP) to get the weight of the index; the sensitivity of the index is sorted by the size of weights. The specific process is as follows [22].

(i) Construct all the judgment matrix of each layer. The proportion of each criterion from the criterion layer in the target measure is not necessarily the same. In the eyes of the decision-makers, they each have a certain proportion, respectively. Use numbers 1-9 and their reciprocal as the scale to define the judgment matrix $A=\left(a_{i j}\right)_{n \times n}$; see Table 3 .

(ii) Use the eigenvector method to calculate weight, as shown in the following formula:

$$
A W=\lambda_{\max } W
$$

where $\lambda_{\max }$ represents the maximum eigenvalue of the judgment matrix.

(iii) Calculate the consistency index CI, as shown in the following formula:

$$
\mathrm{CI}=\frac{\lambda_{\max }-n}{n-1}
$$

(iv) Find the average random consistency index RI (see Table 4) and then calculate the consistency ratio CR, as shown in the following formula:

$$
\mathrm{CR}=\frac{\mathrm{CI}}{\mathrm{RI}}
$$

TABLE 4: Average random consistency index.

\begin{tabular}{ccccccccccc}
\hline$n$ & 1 & 2 & 3 & 4 & 5 & 6 & 7 & 8 & 9 & 10 \\
\hline RI & 0 & 0 & 0.52 & 0.89 & 1.12 & 1.24 & 1.36 & 1.41 & 1.46 & 1.49 \\
\hline
\end{tabular}

When CR $<0.10$, the consistency of judgment matrix is acceptable; otherwise the judgment matrix should be properly modified.

(2) In the evaluation of suppliers, the high score generally represents the stronger competitiveness of the supplier and more opportunities for cooperation. Therefore, in order to avoid the impact of the results of the individual coefficients, catastrophe theory is used to calculate $I_{P}\left(I_{P 1}, I_{P 2}, I_{P 3}\right.$, $\left.\ldots, I_{P N}\right), I_{E}\left(I_{E 1}, I_{E 2}, I_{E 3}, \ldots, I_{E N}\right), I_{G}\left(I_{G 1}, I_{G 2}, I_{G 3}, \ldots, I_{G N}\right)$, $I_{C}\left(I_{C 1}, I_{C 2}, I_{C 3}, \ldots, I_{C N}\right)$.

(3) The following improvements can be made in the evaluation of suppliers.

Supplier total score $S=$ basic coefficient $B \times$ cooperation index $C$; basic coefficient $B=$ product coefficient $P \times$ enterprise coefficient $E \times$ green coefficient $G$, as shown in Figure 3 . Product coefficient $=$ product index $\div$ product standard value; that is $P=I_{P} / p$; similarly, enterprise coefficient $=$ enterprise index $\div$ enterprise standard value; that is, $E=$ $I_{E} / e$; green coefficient $=$ green development index $\div$ green standard value; that is, $G=I_{G} / g$. Among them, $p=\min \left\{I_{P 1}\right.$, $\left.I_{P 2}, I_{P 3}, \ldots, I_{P N}\right\}, e=\min \left\{I_{E 1}, I_{E 2}, I_{E 3}, \ldots, I_{E N}\right\}$, and $g=$ $\min \left\{I_{G 1}, I_{G 2}, I_{G 3}, \ldots, I_{G N}\right\}$.

\section{Case Analysis}

Housing industrialization is mainly composed of the skeleton construction system and the infill construction system. The infill construction system can be realized through the factory production of the infill parts and on-site assembly for the industrialized production. The unit bathroom of the infill construction system adopts the industrialized production; it means that the wall, ground, and roof of the unit bathroom are produced in the factory and assembled easily, quickly at the construction site. This advanced technology has replaced the traditional way of doing the bathroom like plaster stick ceramics. This way of industrialization is the future development direction of the bathroom.

Whether from the material or construction, the unit bathroom compared to the traditional bathroom renovation project has lots of obvious advantages in many aspects, such as water saving, energy saving, material saving, earth saving, and green environmental protection. The extensive application of the unit bathroom will undoubtedly promote 
the process of housing industrialization in China; it not only improves the quality of bathroom decoration but also reduces the energy consumption and pollution emissions, which is in line with China's long-term sustainable development goal.

A real estate developer intends to adopt the unit bathroom in their new real estate project and requires the construction parts suppliers to provide products which have the advantages of green environmental protection, comfortability, energy consumption, and efficient use. The real estate developer needs to choose the best one from the five qualified suppliers (resp., represented by A, B, C, D, and E).

A company is an integrated company that specializes in the research, development, production, and sales of highend honeycomb composites materials and high-end application products, with the leading technology and intellectual property of the honeycomb composites materials. The characteristics of the unit bathroom that A company produces are as follows: (1) The unit bathroom adopts the environmentally friendly materials. For instance, the honeycomb composites materials are composite from the ceramic tile, aluminum honeycomb, and polyurethane, which do not contain formaldehyde and other harmful substances. (2) The unit bathroom adopts industrialized production method, which can reduce the "three wastes" emissions and reduce the pollution of the environment; all materials can be degraded and recovered and will not cause any pollution to the environment. The production process is very environmentally friendly. (3) The installation of the unit bathroom adopts the dry construction installation, which can make installation in the approximate way like putting up building blocks, with no noise, avoiding a nuisance, breaking through 10-hour work time limit of decoration works in the city. This way of installation can reduce the construction waste. As a result it can avoid the high cost of garbage disposal and enhance the social responsibility of the company.

B company has more than 40 direct service agencies, which can provide customers with timely, thoughtful presales and after-sales service. The product market share of $\mathrm{B}$ company is higher, especially in the real estate market and chain hotel market. The characteristics of the unit bathroom that B company produces are as follows. (1) The production process of the unit bathroom is environmentally friendly. The production workshops use the design of permeability, which enhances the air flow of the workshops and provides enough natural lighting to reduce energy consumption. The plant adopts internal water circulation system. The used water will be purified and put back into the circulatory system. (2) The unit bathroom adopts high-tech materials. For instance, the sheet molding compound (SMC) material which can be used as the tableware will have no harmful gas emissions and radioactive pollution. (3) The used process of the unit bathroom is of low carbon and energy saving. SMC material has the heat insulation performance, and there is a heat preservation buffer layer between the unit bathroom and the wall, which can avoid the heat absorbed by the building.

C company is a detail-oriented enterprise, which takes the humanized design as the core and meets the needs of customers in different areas. Its products are involved in a
TABle 5: Product index judgment matrix of secondary indicators relative to primary indicators.

\begin{tabular}{lccc}
\hline & $I_{P 1}$ & $I_{P 2}$ & $I_{P 3}$ \\
\hline$I_{P 1}$ & 1 & 2 & 3 \\
$I_{P 2}$ & $1 / 2$ & 1 & 2 \\
$I_{P 3}$ & $1 / 3$ & $1 / 2$ & 1 \\
\hline
\end{tabular}

Calculation of MATLAB software: $\mathrm{CI}=0.0046, \mathrm{CR}=0.0079$; according to the consistency test, the vector weight $Q$ is $Q=0.5396,0.2970,0.1634$.

wide range, mainly in hotels, hospitals, residential, shipbuilding, and other fields. The characteristics of the unit bathroom that $\mathrm{C}$ company produces are as follows. (1) The underpan, walls, and plates of the unit bathroom have high temperature and high pressure molding, and the underpan is a whole waterproof plate, which has a good antileakage effect. (2) The unit bathroom adopts the sheet molding compound (SMC) material, which is a kind of environmentally friendly hightech material, safe, strong, bright, and antiaging. (3) The unit bathroom can be installed by the way of dry construction; it can be used on the day when the installation is completed, and this will greatly shorten the construction cycle.

The characteristics of the unit bathroom that D company produces are as follows. (1) The unit bathroom body adopts the environmentally friendly polymethyl methacrylate (PMMA) sheets, having good transparency, stability, weather resistance, insulation, and mechanical strength. (2) The surface of the unit bathroom underpan is made of carbon steel which is composite of high purity steel and rubber. It has the characteristics of wear resistance, fire resistance, slip resistance, and insulation. (3) The whole structure of the unit bathroom adopts modular disassembling fastener design, which has the advantage of quick installation, does not produce the construction garbage, and makes the installation of 100 sets of the unit bathroom complete within 1 to 2 weeks.

The characteristics of the unit bathroom that E company produces are as follows. (1) The unit bathroom body uses the environmentally friendly Vinyl-Coated Metal (VCM), and its surface has been attached to the coated PVC membrane, which has rich colors, good decorative effect, and high surface gloss and can meet wear resistance, corrosion resistance, oil stain resistance, easy cleaning, and so forth. (2) The unit bathroom adopts an integrated professional waterproof underpan, with excellent waterproof effect.

6.1. Basic Data Processing. In order to obtain the accuracy and convenience in the calculation process, this paper uses the MATLAB software to calculate the weight of analytic hierarchy process. First of all, compare the importance of each project evaluation index by the leader of the project, experts, and relevant person, so as to obtain the judgment matrix. Then calculate the weight of each level to determine the sensitivity indicators sorting.

In the weight calculation process of product index, the judgment matrix of secondary indicators relative to primary indicators is shown in Table 5, and the judgment matrix of tertiary indicators relative to secondary indicators is shown in Table 6. 
TABLE 6: Product index judgment matrix of tertiary indicators relative to secondary indicators.

(a)

\begin{tabular}{lcccc}
\hline & $I_{P 11}$ & $I_{P 12}$ & $I_{P 13}$ & $I_{P 14}$ \\
\hline$I_{P 11}$ & 1 & $1 / 3$ & $1 / 4$ & $1 / 5$ \\
$I_{P 12}$ & 3 & 1 & $1 / 2$ & $1 / 2$ \\
$I_{P 13}$ & 4 & 2 & 1 & $1 / 2$ \\
$I_{P 14}$ & 5 & 2 & 2 & 1 \\
\hline
\end{tabular}

Calculation of MATLAB software: $\mathrm{CI}=0.0189, \mathrm{CR}=0.0210$; according to the consistency test, the vector weight $Q$ is $Q=0.0738,0.1925,0.2944,0.4393$.

(b)

\begin{tabular}{lccc}
\hline & $I_{P 21}$ & $I_{P 22}$ & $I_{P 23}$ \\
\hline$I_{P 21}$ & 1 & 7 & 3 \\
$I_{P 22}$ & $1 / 7$ & 1 & $1 / 2$ \\
$I_{P 23}$ & $1 / 3$ & 2 & 1 \\
\hline
\end{tabular}

Calculation of MATLAB software: $\mathrm{CI}=0.0013, \mathrm{CR}=0.0023$; according to the consistency test, the vector weight $Q$ is $Q=0.6817,0.1025,0.2158$.

(c)

\begin{tabular}{lccc}
\hline & $I_{P 31}$ & $I_{P 32}$ & $I_{P 33}$ \\
\hline$I_{P 31}$ & 1 & $1 / 7$ & 1 \\
$I_{P 32}$ & 7 & 1 & 7 \\
$I_{P 33}$ & 1 & $1 / 7$ & 1 \\
\hline
\end{tabular}

Calculation of MATLAB software: $\mathrm{CI}=6.6613 e-16$, $\mathrm{CR}=1.1485 e-15$; according to the consistency test, the vector weight $Q$ is $Q=0.1110,0.7778$, 0.1112 .

TABLE 7: Enterprise index judgment matrix of secondary indicators relative to primary indicators.

\begin{tabular}{ccccc}
\hline & $I_{E 1}$ & $I_{E 2}$ & $I_{E 3}$ & $I_{E 4}$ \\
\hline$I_{E 1}$ & 1 & 3 & 3 & 5 \\
$I_{E 2}$ & $1 / 3$ & 1 & 2 & 3 \\
$I_{E 3}$ & $1 / 3$ & $1 / 2$ & 1 & 3 \\
$I_{E 4}$ & $1 / 5$ & $1 / 3$ & $1 / 3$ & 1 \\
\hline
\end{tabular}

Calculation of MATLAB software: $\mathrm{CI}=0.0347, \mathrm{CR}=0.0386$; according to the consistency test, the vector weight $Q$ is $Q=0.5167,0.2382,0.1682,0.0769$.

In the weight calculation process of enterprise index, the judgment matrix of secondary indicators relative to primary indicators is shown in Table 7, and the judgment matrix of tertiary indicators relative to secondary indicators is shown in Table 8.

In the weight calculation process of green development index, the judgment matrix of secondary indicators relative to primary indicators is shown in Table 9, and the judgment matrix of tertiary indicators relative to secondary indicators is shown in Table 10.

Because each of the cooperation ability index $\left(I_{C}\right)$ and recycling and utilization $\left(I_{G 4}\right)$ only contains two indicators, these two indexes' weights are given by the leader of the project, experts, and relevant person directly. We used the expert scoring method to score the underlying indicators of each supplier, so as to determine the green building parts supplier selection index system and standard data, as shown in Table 11.
TABLE 8: Enterprise index judgment matrix of tertiary indicators relative to secondary indicators.

(a)

\begin{tabular}{lcccc}
\hline & $I_{E 11}$ & $I_{E 12}$ & $I_{E 13}$ & $I_{E 14}$ \\
\hline$I_{E 11}$ & 1 & 2 & 5 & 7 \\
$I_{E 12}$ & $1 / 2$ & 1 & 3 & 5 \\
$I_{E 13}$ & $1 / 5$ & $1 / 3$ & 1 & 5 \\
$I_{E 14}$ & $1 / 7$ & $1 / 5$ & $1 / 5$ & 1 \\
\hline
\end{tabular}

Calculation of MATLAB software: $\mathrm{CI}=0.0640, \mathrm{CR}=0.0711$; according to the consistency test, the vector weight $Q$ is $Q=0.5155,0.2926,0.1416,0.0503$.

(b)

\begin{tabular}{lccc}
\hline & $I_{E 21}$ & $I_{E 22}$ & $I_{E 23}$ \\
\hline$I_{E 21}$ & 1 & $1 / 5$ & $1 / 3$ \\
$I_{E 22}$ & 5 & 1 & 2 \\
$I_{E 23}$ & 3 & $1 / 2$ & 1 \\
\hline
\end{tabular}

Calculation of MATLAB software: $\mathrm{CI}=0.0018, \mathrm{CR}=0.0032$; according to the consistency test, the vector weight $Q$ is $Q=0.1095,0.5816,0.3090$.

(c)

\begin{tabular}{lcccc}
\hline & $I_{E 31}$ & $I_{E 32}$ & $I_{E 33}$ & $I_{E 34}$ \\
\hline$I_{E 31}$ & 1 & $1 / 5$ & $1 / 3$ & $1 / 3$ \\
$I_{E 32}$ & 5 & 1 & 3 & 3 \\
$I_{E 33}$ & 3 & $1 / 3$ & 1 & 1 \\
$I_{E 34}$ & 3 & $1 / 3$ & 1 & 1 \\
\hline
\end{tabular}

Calculation of MATLAB software: $\mathrm{CI}=0.0145, \mathrm{CR}=0.0161$; according to the consistency test, the vector weight $Q$ is $Q=0.0781,0.5222,0.1998,0.1998$.

(d)

\begin{tabular}{lccc}
\hline & $I_{E 41}$ & $I_{E 42}$ & $I_{E 43}$ \\
\hline$I_{E 41}$ & 1 & 2 & 3 \\
$I_{E 42}$ & $1 / 2$ & 1 & 2 \\
$I_{E 43}$ & $1 / 3$ & $1 / 2$ & 1 \\
\hline
\end{tabular}

Calculation of MATLAB software: $\mathrm{CI}=0.0046, \mathrm{CR}=0.0079$; according to the consistency test, the vector weight $Q$ is $Q=0.5396,0.2970,0.1634$.

TABLE 9: Green development index judgment matrix of secondary indicators relative to primary indicators.

\begin{tabular}{lcccc}
\hline & $I_{G 1}$ & $I_{G 2}$ & $I_{G 3}$ & $I_{G 4}$ \\
\hline$I_{G 1}$ & 1 & $1 / 3$ & $1 / 5$ & 2 \\
$I_{G 2}$ & 3 & 1 & $1 / 3$ & 3 \\
$I_{G 3}$ & 5 & 3 & 1 & 6 \\
$I_{G 4}$ & $1 / 2$ & $1 / 3$ & $1 / 6$ & 1 \\
\hline
\end{tabular}

Calculation of MATLAB software: $\mathrm{CI}=0.0263, \mathrm{CR}=0.0292$; according to the consistency test, the vector weight $Q$ is $Q=0.1124,0.2445,0.5677,0.0754$.

6.2. Calculation Process. Taking supplier A as an example, the calculation of the product index is

$$
\begin{aligned}
& I_{P 1}=\frac{\left(\sqrt{I_{P 14}}+\sqrt[3]{I_{P 13}}+\sqrt[4]{I_{P 12}}+\sqrt[5]{I_{P 11}}\right)}{4}=8.3666, \\
& I_{P 2}=\frac{\left(\sqrt{I_{P 21}}+\sqrt[3]{I_{P 23}}+\sqrt[4]{I_{P 22}}\right)}{3}=6.5083
\end{aligned}
$$


TABLE 10: Green development index judgment matrix of tertiary indicators relative to secondary indicators.

(a)

\begin{tabular}{lcccc}
\hline & $I_{G 11}$ & $I_{G 12}$ & $I_{G 13}$ & $I_{G 14}$ \\
\hline$I_{G 11}$ & 1 & 2 & 6 & 5 \\
$I_{G 12}$ & $1 / 2$ & 1 & 3 & 2 \\
$I_{G 13}$ & $1 / 6$ & $1 / 3$ & 1 & $1 / 2$ \\
$I_{G 14}$ & $1 / 5$ & $1 / 5$ & 2 & 1 \\
\hline
\end{tabular}

Calculation of MATLAB software: $\mathrm{CI}=-0.0428, \mathrm{CR}=-0.0475$; according to the consistency test, the vector weight $Q$ is $Q=0.5469,0.2589,0.0814$, 0.1128 .

(b)

\begin{tabular}{lcccc}
\hline & $I_{G 21}$ & $I_{G 22}$ & $I_{G 23}$ & $I_{G 24}$ \\
\hline$I_{G 21}$ & 1 & 2 & 3 & 5 \\
$I_{G 22}$ & $1 / 2$ & 1 & 2 & 4 \\
$I_{G 23}$ & $1 / 3$ & $1 / 2$ & 1 & 3 \\
$I_{G 24}$ & $1 / 5$ & $1 / 4$ & $1 / 3$ & 1 \\
\hline
\end{tabular}

Calculation of MATLAB software: $\mathrm{CI}=0.0170, \mathrm{CR}=0.0189$; according to the consistency test, the vector weight $Q$ is $Q=0.4729,0.2844,0.1699,0.0729$.

(c)

\begin{tabular}{lcccc}
\hline & $I_{G 31}$ & $I_{G 32}$ & $I_{G 33}$ & $I_{G 34}$ \\
\hline$I_{G 31}$ & 1 & $1 / 3$ & $1 / 3$ & $1 / 7$ \\
$I_{G 32}$ & 3 & 1 & 1 & $1 / 3$ \\
$I_{G 33}$ & 3 & 1 & 1 & $1 / 3$ \\
$I_{G 34}$ & 7 & 3 & 3 & 1 \\
\hline
\end{tabular}

Calculation of MATLAB software: $\mathrm{CI}=0.0026, \mathrm{CR}=0.0029$; according to the consistency test, the vector weight $Q$ is $Q=0.0687,0.1931,0.1931,0.5451$.

$$
\begin{gathered}
I_{P 3}=\frac{\left(\sqrt{I_{P 32}}+\sqrt[3]{I_{P 33}}+\sqrt[4]{I_{P 31}}\right)}{3}=6.4080 \\
I_{P}=\frac{\left(\sqrt{I_{P 1}}+\sqrt[3]{I_{P 2}}+\sqrt[4]{I_{P 3}}\right)}{3}=6.3506 .
\end{gathered}
$$

In the same way, the calculation result of enterprise index is

$$
\begin{aligned}
& I_{E 1}=\frac{\left(\sqrt{I_{E 11}}+\sqrt[3]{I_{E 12}}+\sqrt[4]{I_{E 13}}+\sqrt[5]{I_{E 14}}\right)}{4}=8.2843 \\
& I_{E 2}=\frac{\left(\sqrt{I_{E 22}}+\sqrt[3]{I_{E 23}}+\sqrt[4]{I_{E 21}}\right)}{3}=6.1276 \\
& I_{E 3}=\frac{\left(\sqrt{I_{E 32}}+\sqrt[3]{I_{E 33}}+\sqrt[4]{I_{E 34}}+\sqrt[5]{I_{E 31}}\right)}{4}=6.9056 \\
& I_{E 4}=\frac{\left(\sqrt{I_{E 41}}+\sqrt[3]{I_{E 42}}+\sqrt[4]{I_{E 43}}\right)}{3}=6.5677 \\
& I_{E}=\frac{\left(\sqrt{I_{E 1}}+\sqrt[3]{I_{E 2}}+\sqrt[4]{I_{E 3}}+\sqrt[5]{I_{E 4}}\right)}{4}=7.7863 .
\end{aligned}
$$

The calculation result of green development index is

$$
\begin{aligned}
& I_{G 1}=\frac{\left(\sqrt{I_{G 11}}+\sqrt[3]{I_{G 12}}+\sqrt[4]{I_{G 14}}+\sqrt[5]{I_{G 13}}\right)}{4}=5.8458, \\
& I_{G 2}=\frac{\left(\sqrt{I_{G 21}}+\sqrt[3]{I_{G 22}}+\sqrt[4]{I_{G 23}}+\sqrt[5]{I_{G 24}}\right)}{4}=8.2600, \\
& I_{G 3}=\frac{\left(\sqrt{I_{G 34}}+\sqrt[3]{I_{G 33}}+\sqrt[4]{I_{G 32}}+\sqrt[5]{I_{G 31}}\right)}{4}=7.8792, \\
& I_{G 4}=\frac{\left(\sqrt{I_{G 42}}+\sqrt[3]{I_{G 41}}\right)}{2}=2.2828 \\
& I_{G}=\frac{\left(\sqrt{I_{G 3}}+\sqrt[3]{I_{G 2}}+\sqrt[4]{I_{G 1}}+\sqrt[5]{I_{G 4}}\right)}{4}=7.5628 .
\end{aligned}
$$

The calculation result of cooperation ability index is

$$
\begin{gathered}
I_{C 1}=\frac{\left(\sqrt{I_{C 11}}+\sqrt[3]{I_{C 12}}\right)}{2}=5.0208 \\
I_{C 2}=\frac{\left(\sqrt{I_{C 22}}+\sqrt[3]{I_{C 21}}\right)}{2}=5.0946 \\
I_{C}=\frac{\left(\sqrt{I_{C 2}}+\sqrt[3]{I_{C 1}}\right)}{2}=3.9695 .
\end{gathered}
$$

The total score of supplier A is

$$
\begin{aligned}
& B=P \times E \times G=\frac{I_{P}}{I_{P 1}} \times \frac{I_{E}}{I_{E 2}} \times \frac{I_{G}}{I_{G 4}}=4.1721, \\
& S=B \times C=4.1721 \times 3.9695=16.5611 .
\end{aligned}
$$

The final scores of the 5 suppliers can be calculated as shown in Table 12.

6.3. Result Analysis. According to the comparative analysis of product index, enterprise index, green development index, cooperation ability index, and total score, it can be seen that the five suppliers do not have a big difference between the various points. If the real estate developer simply considers only one indicator among them, such as cooperation ability index, then supplier $\mathrm{C}$ is selected as the best. It will be a wrong decision because supplier A has the highest scores in the other indexes and total performance. The potential strength of supplier A is stronger than supplier C's, so that supplier A will be the best choice. This result happens to confirm that the Kent index itself does not avoid the impact of subjective factors but takes measures to carry out a comprehensive analysis to minimize the subjective impact, while the application of catastrophe theory is also well to avoid the influence of the weight on the result.

\section{Conclusion and Suggestion}

This paper analyzes the inherent requirements of the green building, meanwhile combines with the characteristics of construction part of housing industrialization, and then puts forward the selection evaluation index system of the green 
TABLE 11: Green building parts supplier selection index system and standard data.

\begin{tabular}{|c|c|c|c|c|c|c|c|c|c|}
\hline \multirow{2}{*}{ Primary index } & \multirow{2}{*}{ Secondary index } & \multirow{2}{*}{ Weight } & \multirow{2}{*}{ Tertiary index } & \multirow{2}{*}{ Weight } & \multicolumn{5}{|c|}{ Supplier/score $(0 \sim 10)$} \\
\hline & & & & & $\mathrm{A}$ & $\mathrm{B}$ & $\mathrm{C}$ & $\mathrm{D}$ & $\mathrm{E}$ \\
\hline \multirow{4}{*}{$I_{P}$} & \multirow{4}{*}{$I_{P 1}$} & \multirow{4}{*}{0.5396} & $I_{P 11}$ & 0.0738 & 8.85 & 8.85 & 8.72 & 9.62 & 9.1 \\
\hline & & & $I_{P 12}$ & 0.1925 & 8.74 & 8.74 & 8.91 & 8.63 & 9.27 \\
\hline & & & $I_{P 13}$ & 0.2944 & 9.05 & 9.05 & 8.93 & 9.02 & 9.13 \\
\hline & & & $I_{P 14}$ & 0.4393 & 9.10 & 9.04 & 9.16 & 8.17 & 7.96 \\
\hline \multirow{3}{*}{$I_{P}$} & \multirow{3}{*}{$I_{P 2}$} & \multirow{3}{*}{0.2970} & $I_{P 21}$ & 0.6817 & 9.74 & 9.74 & 9.78 & 9.53 & 9.67 \\
\hline & & & $I_{P 22}$ & 0.1025 & 2.49 & 2.49 & 2.85 & 2.51 & 2.37 \\
\hline & & & $I_{P 23}$ & 0.2158 & 9.68 & 9.68 & 9.62 & 9.65 & 9.81 \\
\hline \multirow{3}{*}{$I_{P}$} & \multirow{3}{*}{$I_{P 3}$} & \multirow{3}{*}{0.1634} & $I_{P 31}$ & 0.1110 & 9.75 & 9.75 & 9.81 & 9.72 & 9.86 \\
\hline & & & $I_{P 32}$ & 0.7778 & 6.67 & 6.67 & 7.79 & 10 & 8.89 \\
\hline & & & $I_{P 33}$ & 0.1112 & 8.72 & 8.72 & 9.37 & 8.85 & 9.17 \\
\hline \multirow{4}{*}{$I_{E}$} & \multirow{4}{*}{$I_{E 1}$} & \multirow{4}{*}{0.5167} & $I_{E 11}$ & 0.5155 & 9.02 & 9.02 & 9.16 & 8.07 & 7.86 \\
\hline & & & $I_{E 12}$ & 0.2926 & 8.54 & 8.54 & 7.54 & 8.32 & 6.74 \\
\hline & & & $I_{E 13}$ & 0.1416 & 8.5 & 8.5 & 7.3 & 9.4 & 10 \\
\hline & & & $I_{E 14}$ & 0.0503 & 8.37 & 8.37 & 8.57 & 8.46 & 9.02 \\
\hline \multirow{3}{*}{$I_{E}$} & \multirow{3}{*}{$I_{E 2}$} & \multirow{3}{*}{0.2382} & $I_{E 21}$ & 0.1095 & 7.26 & 7.26 & 6.85 & 6.91 & 7.03 \\
\hline & & & $I_{E 22}$ & 0.5816 & 6.75 & 7.75 & 7.39 & 7.28 & 8.64 \\
\hline & & & $I_{E 23}$ & 0.3090 & 6.73 & 6.73 & 6.81 & 7.13 & 6.79 \\
\hline \multirow{4}{*}{$I_{E}$} & & & $I_{E 31}$ & 0.0781 & 4.15 & 4.25 & 4.28 & 4.12 & 4.07 \\
\hline & $I_{\mathrm{D}}$ & 01682 & $I_{E 32}$ & 0.5222 & 3.18 & 3.18 & 3.86 & 4.01 & 3.06 \\
\hline & $1_{E 3}$ & & $I_{E 33}$ & 0.1999 & 8.73 & 8.73 & 8.92 & 8.31 & 8.47 \\
\hline & & & $I_{E 34}$ & 0.1997 & 9.04 & 9.04 & 8.63 & 9.27 & 9.62 \\
\hline & & & $I_{E 41}$ & 0.5396 & 8.65 & 8.65 & 8.79 & 8.24 & 8.54 \\
\hline$I_{E}$ & $I_{E 4}$ & 0.0769 & $I_{E 42}$ & 0.2970 & 7.52 & 7.52 & 8.16 & 7.49 & 7.51 \\
\hline & & & $I_{E 43}$ & 0.1634 & 7.73 & 7.73 & 7.46 & 8.47 & 7.82 \\
\hline & & & $I_{G 11}$ & 0.5383 & 2.51 & 2.51 & 2.79 & 2.63 & 2.47 \\
\hline & & 01124 & $I_{G 12}$ & 0.2531 & 3.77 & 3.77 & 3.69 & 4.38 & 3.95 \\
\hline$I_{G}$ & $I_{G 1}$ & 0.1124 & $I_{G 13}$ & 0.0790 & 5.84 & 5.84 & 5.73 & 6.08 & 6.39 \\
\hline & & & $I_{G 14}$ & 0.1297 & 2.7 & 2.7 & 2.63 & 2.34 & 3.27 \\
\hline & & & $I_{G 21}$ & 0.4729 & 9.24 & 9.24 & 9.47 & 9.17 & 9.06 \\
\hline$I_{\mathrm{L}}$ & $L_{0}$ & 02445 & $I_{G 22}$ & 0.2844 & 8.52 & 8.52 & 9.02 & 8.73 & 8.85 \\
\hline$I_{G}$ & $I_{G 2}$ & & $I_{G 23}$ & 0.1699 & 9.27 & 9.27 & 9.16 & 9.37 & 9.13 \\
\hline & & & $I_{G 24}$ & 0.0729 & 6.04 & 6.04 & 6.13 & 6.21 & 5.95 \\
\hline & & & $I_{G 31}$ & 0.0687 & 7.35 & 7.35 & 7.28 & 7.4 & 7.39 \\
\hline$I_{L_{1}}$ & $I_{C_{3}}$ & 0.5677 & $I_{G 32}$ & 0.1930 & 5.74 & 5.84 & 5.93 & 6.18 & 6.39 \\
\hline$I_{G}$ & $I_{G 3}$ & $0.56 / 7$ & $I_{G 33}$ & 0.1932 & 5.64 & 5.94 & 6.43 & 6.48 & 6.19 \\
\hline & & & $I_{G 34}$ & 0.5451 & 9.37 & 9.47 & 9.26 & 9.57 & 9.13 \\
\hline & & 0.0754 & $I_{G 41}$ & 0.4000 & 2.52 & 2.53 & 2.78 & 2.73 & 2.47 \\
\hline$I_{G}$ & $I_{G 4}$ & 0.0754 & $I_{G 42}$ & 0.6000 & 0.85 & 0.94 & 1.83 & 2.18 & 1.49 \\
\hline$I_{\mathrm{r}}$ & & 04500 & $I_{C 11}$ & 0.6000 & 8.63 & 8.72 & 9.47 & 8.95 & 9.27 \\
\hline$I_{C}$ & $I_{C 1}$ & 0.4500 & $I_{C 12}$ & 0.4000 & 9.04 & 9.04 & 9.16 & 8.17 & 7.96 \\
\hline$I_{2}$ & & 0.5500 & $I_{C 21}$ & 0.4500 & 8.47 & 8.38 & 8.58 & 8.66 & 9.02 \\
\hline$I_{C}$ & $I_{\mathrm{C} 2}$ & 0.5500 & $I_{C 22}$ & 0.5500 & 9.34 & 9.44 & 9.57 & 9.27 & 9.06 \\
\hline
\end{tabular}

building parts suppliers. In order to avoid the influence of subjective factors in the evaluation process, the method which is combined with Kent index and catastrophe theory is introduced; meanwhile some improvements are made to the method. This paper takes a practical case to verify the improved method. The result of the practical case shows that this improved method can effectively reduce the influence of subjective factors, abate the effect of a single factor on the selection result, achieve the comprehensive consideration of the selection process, and lay a certain foundation for green 
TABLE 12: Final scores of five suppliers.

\begin{tabular}{lcccrr}
\hline Index & $\mathrm{A}$ & $\mathrm{B}$ & $\mathrm{C}$ & $\mathrm{D}$ & $\mathrm{E}$ \\
\hline Product coefficient & 0.9910 & 0.9908 & 0.9723 & 0.9820 & 0.9780 \\
Enterprise coefficient & 1.2707 & 1.2363 & 1.2500 & 1.2467 & 1.2026 \\
Green coefficient & 3.3130 & 3.2491 & 2.7661 & 2.6623 & 2.9573 \\
Cooperation index & 3.9695 & 3.9732 & 3.9964 & 3.9686 & 12.9346 \\
Total score & 16.5611 & 15.8123 & 13.4351 & & 13.8137 \\
\hline
\end{tabular}

building supplier selection and evaluation. The improved method has absorbed the merits of the two methods and hence is of applicative value.

Adopting the comprehensive application of Kent index method and catastrophe theory to evaluate and select the green building parts suppliers is in the trial stage. The weight of each evaluation index and the corresponding scores still rely on the expert scoring method to determine. Therefore, the accuracy and rationality of this method are open to discussion. It is hoped that this method can be further improved after the combination of more practical cases.

\section{Competing Interests}

The authors declare no conflict of interests.

\section{Acknowledgments}

The authors acknowledge funding through projects of Sichuan Province Education Department Scientific Research (16SB0064) and Young Scholars Development Fund SWPU (200931010056).

\section{References}

[1] L. Zhongfu, L. Kangjuan, and Z. Rui, "Research \& development for housing industrialization in China," International Journal for Housing Science and Its Applications, vol. 4, no. 27, pp. 313-322, 2003.

[2] Z. Shengqin and F. Xuedong, "Analysis of the key affecting factors of China's housing industrialization development," Journal of Engineering Management, vol. 29, no. 6, pp. 54-58, 2015.

[3] J. Zhang and L. Gu, "Development status of green building in China, challenges and policy recommendations," Energy of China, vol. 34, no. 12, pp. 19-24, 2012.

[4] H. Qi, The Problems and Strategies of Chinese Housing Industrialization, Hua Zhong Normal University, Wuhan, China, 2007.

[5] C. Xu and Y. Y. Pei, "Research on the strategy of using housing industrialization to promoting domestic construction of villages and small towns," Applied Mechanics and Materials, vol. 584-586, pp. 2518-2521, 2014.

[6] L.-F. Shen and Q.-M. Li, "Research on the real estate enterprises development strategy facing the housing industrialization," in Proceedings of the International Seminar on Business and Information Management (ISBIM '08), vol. 2, pp. 378-381, Wuhan, China, December 2008.

[7] M. Longquan, L. Yan, and D. Wentao, "Research on the path of housing industrialization on the basis of enterprise strategic alliance," in Proceedings of the 16th International Symposium on Advancement of Construction Management and Real Estate (CRIOCM '11), pp. 366-370, September 2011.

[8] J.-W. Wang and S.-W. Guo, "Research of construction supplier selection model based on grey relevancy," Journal of Wuhan University of Technology, vol. 29, no. 3, pp. 153-156, 2007.

[9] J. Yan, T. Zhang, Z. L. Wu et al., "Data envelopment analysis and its application in supplier selection," in Proceedings of the 8th International Conference of Chinese Logistics and Transportation Professionals-Logistics: The Emerging Frontiers of Transportation and Development in China, pp. 1483-1488, 2009.

[10] R. Farzipoor Saen, "Supplier selection by the pair of nondiscretionary factors-imprecise data envelopment analysis models," Journal of the Operational Research Society, vol. 60, no. 11, pp. $1575-1582,2009$.

[11] Y. Yang, H. Lu, and J. Zhang, "A fuzzy multi-objective decision model considering competition for the logistics supplier selection," in Proceedings of the 2010 International Conference of Logistics Engineering and Management-Logistics for Sustained Economic Development: Infrastructure, Information, Integration (ICLEM '10), vol. 387, pp. 4460-4465, Chengdu, China, October 2010.

[12] P. Peng and J. Li, "Research on construction supplier selection based on entropy weight TOPSIS," Journal of Jiangxi University of Science and Technology, vol. 31, no. 2, pp. 67-69, 2010.

[13] L. Ruan and J. Chen, "Green building supplier selection based on fuzzy VIKOR method," Statistics \& Decision, no. 21, pp. 6265, 2011.

[14] V. I. Arnol'd, Dynamical Systems V-Bifurcation Theory and Catastrophe Theory, The Science Publishing Company, 2009.

[15] H. Jian, P. HaiZe, C. MengJie, and M. Wei, "Research on construction risk of foundation pit of subway station based on rough set theory and catastrophe progression method," The Electronic Journal of Geotechnical Engineering, vol. 21, no. 4, pp. 4435-4443, 2016.

[16] L. Xinxin, X. Xiuli, and L. Xuehong, "Assessment of bridge construction safety risk based on kent index method," China Safety Science Journal, vol. 23, no. 6, pp. 165-171, 2013.

[17] L. Zhao, H. Lu, M.-Y. Wang, J.-H. Xiao, and B.-H. Yang, "Application study of W Kent index method on risk assessment in subway engineering construction," Journal of Wuhan University of Technology, vol. 34, no. 12, pp. 97-102, 2012.

[18] Z. Xiaoyun and J. Ling, "A study on the selection of construction component suppliers in the process of housing industrialization," East China Economic Management, vol. 27, no. 10, pp. 9397, 2013.

[19] Q. Lu and Y. Hui, "Selection of assessment index of building subassembly greenness based on full lifecycle theory," Engineering Construction, vol. 38, no. 4, pp. 1-4, 2006.

[20] H. Yantao, "Study of the construction parts greenness assessment system," Journal of Xian University of Architecture \& Technology, vol. 39, no. 4, pp. 524-528, 2007. 
[21] P. HaiZe, M. Wei, C. Mengjie, and H. Jian, "The application of the LEED in subway station construction stage," The Electronic Journal of Geotechnical Engineering, vol. 20, no. 24, pp. 1194511952, 2015.

[22] D. Xue, L. Jiaming, Z. Haojian et al., "Research on computation methods of AHP wight vector and its applications," Mathematics in Practice and Theory, vol. 7, no. 42, pp. 95-100, 2012. 

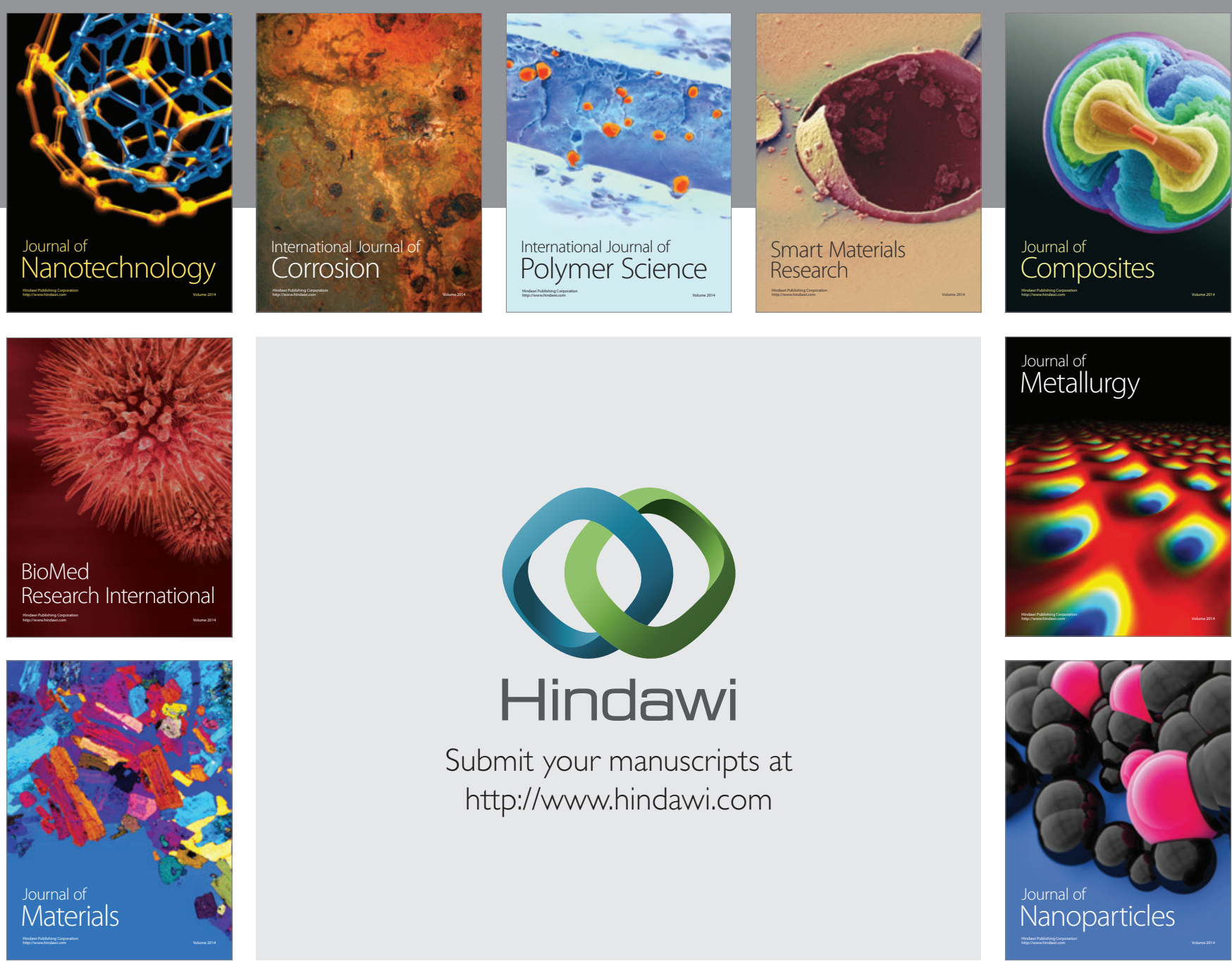

\section{Hindawi}

Submit your manuscripts at

http://www.hindawi.com

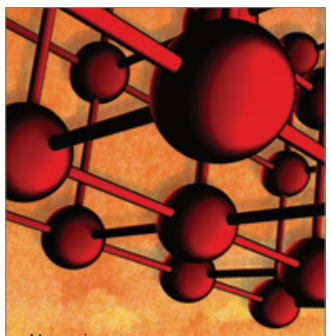

Materials Science and Engineering
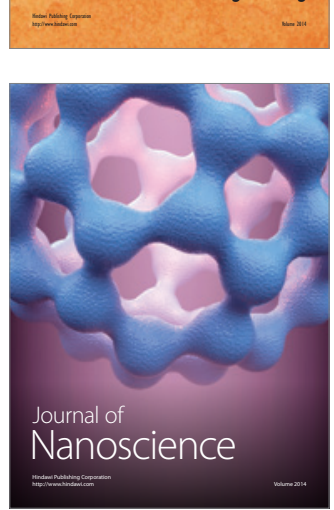
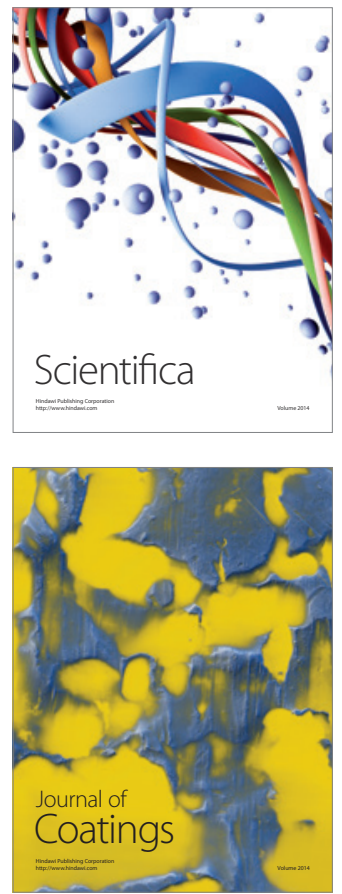
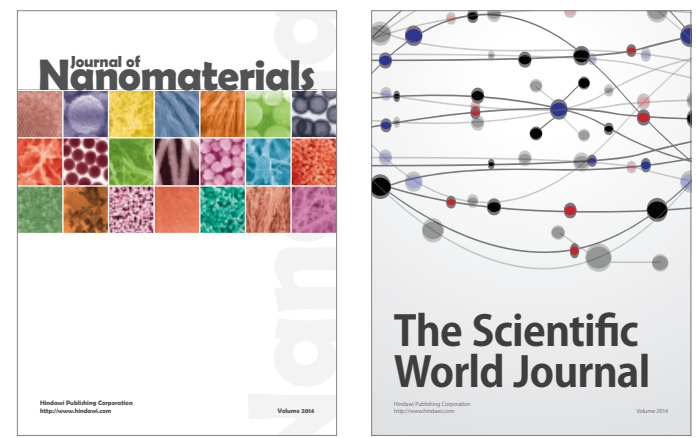

The Scientific World Journal
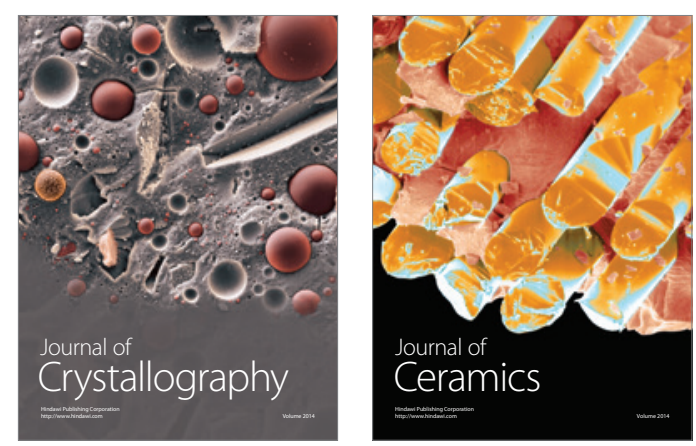
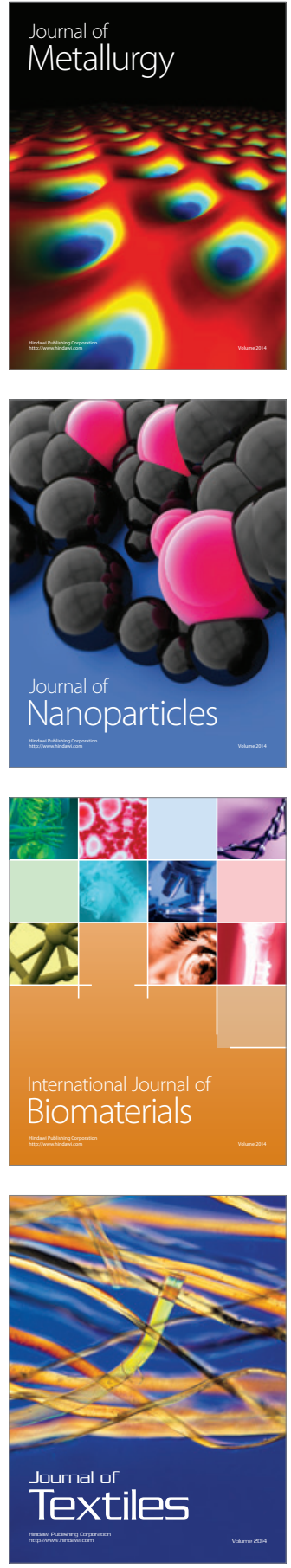